\title{
Children's comprehension of prosodically marked focus in Hungarian: How mandatory syntactic focus-marking affects the trajectory of acquisition
}

\author{
Balázs SURÁNYI* and Lilla PINTÉR ${ }^{* *}$ \\ ${ }^{\star}$ Hungarian Research Centre for Linguistics \& Pázmány Péter Catholic University and ${ }^{\star}$ Pázmány Péter \\ Catholic University \& Hungarian Research Centre for Linguistics \\ Address for correspondence: Balázs Surányi, Hungarian Research Centre for Linguistics 1394 Budapest, \\ P.O. Box 360, Hungary. E-mail: suranyi@nytud.hu
}

(Received 13 March 2020; revised 16 December 2020; accepted 30 March 2021;

first published online 19 May 2021)

\begin{abstract}
This study investigates children's identification of prosodic focus in Hungarian, a language in which syntactic focus-marking is mandatory. Assuming that regular syntactic focusmarking diminishes the disambiguating role of prosodic marking in acquisition, we expected that in sentences in which focus is only disambiguated by prosody, adult-like comprehension of prosodic focus-marking should be delayed in comparison to the Germanic and Romance languages investigated previously using the same experimental method that we adopted. Our results, confirming this prediction, suggest that the developmental trajectory of the comprehension of prosodic focus-marking may be substantially affected by cross-linguistic grammatical variation in the marking of focus.
\end{abstract}

Keywords: prosodic focus-marking; syntactic focus-marking; focus comprehension; full competence; Hungarian

\section{Introduction}

It is beyond reasonable doubt that children learn to produce utterances that conform to the prosodic patterns licensed by their language at a very young age, usually earlier than they have mastered a significant part of the syntax of their language (Bloom, 1970; Brown, 1973; Lieberman, 1967; Menyuk, 1969). Relatedly, children have the competence to perceive prosodic information like pitch, lexical stress and prosodic phrasing from the first months of life on (Gervain \& Werker, 2013; Höhle, Bijeljac-Babic, Herold, Weissenborn \& Nazzi, 2009; Schmitz, Höhle, Müller \& Weissenborn, 2006; Wellmann, Holzgrefe, Truckenbrodt, Wartenburger \& Höhle, 2012).

In line with this, in the few (predominantly, Germanic and Romance) languages in which prosodic focus-marking has been experimentally tested in child language, it unrestricted re- use, distribution and reproduction, provided the original article is properly cited. 
appears that it is produced in an adult-like fashion in many respects at an early age (Hornby, 1971; Sauermann, Höhle, Chen \& Järvikivi, 2011; Wieman, 1976; Yang \& Chen, 2018).

These findings from production may be set in contrast with a range of findings from the acquisition of the prosodic marking of information structure in comprehension, which has typically been described as a protracted developmental process that is delayed as compared to production.

Hornby's (1971) and Cruttenden's (1985) picture selection tasks, which were used to test six- to ten-year-old English-speaking children, showed that even ten-year-olds cannot exploit accent patterns to identify contrastive information or the topiccomment structure of a sentence. Cutler and Swinney (1987) failed to find an adult-like advantage for detecting an accented word in a sentence (compared to its unaccented occurrence) in English-speaking children under the age of six years. Wells, Peppé and Goulandris (2004) tested English-speaking five- and thirteen-year-old children. While in a production task involving corrective focus five-year-olds accentuated the focused constituents in the majority of their utterances (with no difference from children of thirteen years of age), they failed to perform above chance level in a corresponding receptive task (with clear improvement by the age of thirteen), which required the identification of the referent of an accented constituent by pointing to a picture. Children up to school age have also been reported to perform poorly on the comprehension of sentences containing a prosodic focus that is associated with a focus particle like 'only' or 'also' (Bergsma, 2006; Costa \& Szendrői, 2006; Gualmini, Maciukaite \& Crain, 2003).

One language in which the acquisition of the comprehension of prosodic focus-marking has been thoroughly studied is Mandarin Chinese; the empirical generalizations, however, are somewhat controversial. In Chen's (1998) study children responded to subject-focus sentences congruently roughly $65 \%$ of the time at age five. By contrast, in a recent experiment relying on a very similar method, Chen, Szendrői, Crain and Höhle (2019) found that three- to five-year-olds corrected subject-focus sentences in a congruent manner only cca. $15 \%$ of the time, significantly less systematically than adults. The reason for the discrepancy between the results of the two studies remains unclear (cf. Chen et al., 2019, p. 29).

It has been argued convincingly that at least some of the suggested cases of a relative delay of prosodic focus comprehension, compared to focus production, are spurious. For instance, Berger and Höhle (2012) demonstrate that, using a method that makes the information associated with the focus particles 'only' and 'also' highly relevant for completing the task (unlike in some earlier experiments), German-learning threeand four-year-olds perform remarkably well with sentences containing them. A general issue arising in truth value judgment tasks that are often used to gauge children's comprehension of focus-marking is that it is not clear whether children judge stimulus sentences based on the pragmatic meaning contributed by focus-marking, or they judge them based only on their semantic meaning, or whether there may be differences between children in terms of which of these they take to be their actual task (Gualmini, Crain, Meroni, Chierchia \& Guasti, 2001; Papafragou \& Musolino, 2003). Online experiments which do not require any explicit judgment are free from this potential problem. Indeed, several eye-tracking studies have found adult-like patterns of focus identification based on prosodic cues in pre-school children (e.g., Höhle, Berger, Müller, Schmitz \& Weissenborn, 2009; Sekerina \& Trueswell, 2012). 
Stimulus sentences that contain focus operators like 'only' or 'also' are especially prone to the methodological challenge mentioned above. This is because in such sentences the judgment requires children not only to identify focus based on its prosodic marking, but also to associate this focus with the focus operator (which may be at a distance from the focus), and to compute the extra semantic meaning components that come with it (such as the exhaustivity contributed by 'only'). Therefore, as pointed out by Szendröi, Bernard, Berger, Gervain and Höhle (2018), children's response profile in such judgment tasks cannot directly reveal their competence in identifying the focus and processing its basic meaning (which is the highlighting of the relevance of a contextually restricted set of alternatives to the focused element, Krifka, 2008), but rather, it reflects their ability to do that AND to perform further (syntactic and) semantic operations.

For these reasons Szendröi et al. (2018) employed a comprehension task in which no extra semantic operations are triggered and no explicit judgment needs to be given. Instead, the task - a resourceful adaptation of the task developed by Hornby (1971) and Chen (1998) - was to correct false critical sentences; felicitous corrections required the accurate identification of focus in the stimulus. It was found that on this task English, French and German children show an adult-like performance pattern already at age three, with no effect of age across the age groups of three-, four-, fiveand six-year-olds. The authors take these results to support a Full Competence view of prosodic focus-marking, according to which the association between prosodic prominence and focus is in place in children's comprehension already at the earliest ages.

As this brief review makes it apparent, the results and conclusions of previous empirical work on the comprehension of prosodic focus-marking in first language acquisition are highly varied. One key source of this variation, as we have seen, lies in the diversity of the methods that have been employed. A much less appreciated further source of variation is the fact that some of the different empirical studies have investigated different languages. Although it has been explicitly viewed as an important factor in the study of the development of focus production (see Chen, 2018 for a recent overview), cross-linguistic variation in the system of focus-marking has not been methodically investigated in the domain of focus COMPREHENSION (for two notable exceptions, see Szendröi et al., 2018, and Chen et al., 2019). The present paper seeks to address this paucity.

\section{Current study}

This paper aims to contribute to the issue of whether and how the development of the comprehension of prosodic focus-marking may be affected by the variation found in the grammatical marking of focus across different languages. The more specific question our study is concerned with is whether and how the presence of systematic syntactic focus-marking (SFM) in a language affects the trajectory of the acquisition of prosodic focus-marking (PFM) in comprehension. We address this question by experimentally investigating the acquisition of PFM in Hungarian, a language in which syntactic focus-marking is essentially mandatory.

The typical word order in Hungarian sentences (containing a definite external argument subject and a definite internal argument object) is $\mathrm{S}$ (ubject)- $\mathrm{V}$ (erb)-O(bject). It is highly common for verbs to have a so-called Verbal Modifier, such as a verbal particle, an infinitival or bare nominal argument, and various kinds of secondary 
predicates, among others (for the notion and subtypes of Verbal Modifier, VM, see É. Kiss, 2002: Section 3.6.3). In 'neutral', broad focus sentences (i.e., those without a narrow focus), the VM occupies an immediately pre-verbal position. In S-VM-V-O sentences the pre-verbal subject is interpreted by default as an aboutness topic (an element that the rest of the sentence, the comment, predicates about; Krifka, 2008), and VM-V-O constitutes the comment. ${ }^{1}$

Focus (not only corrective focus, but also ordinary information focus) is marked obligatorily by word order: the focused phrase must be fronted to a position that is left-adjacent to the verb. In sentences with a pre-verbal narrow focus, the VM must follow the verb. As a consequence, the position of the VM is a syntactic cue that distinguishes a pre-verbal topic (1a), in the case of which the VM immediately precedes the verb, from a pre-verbal focus (1b), in the case of which the VM must occur post-verbally.

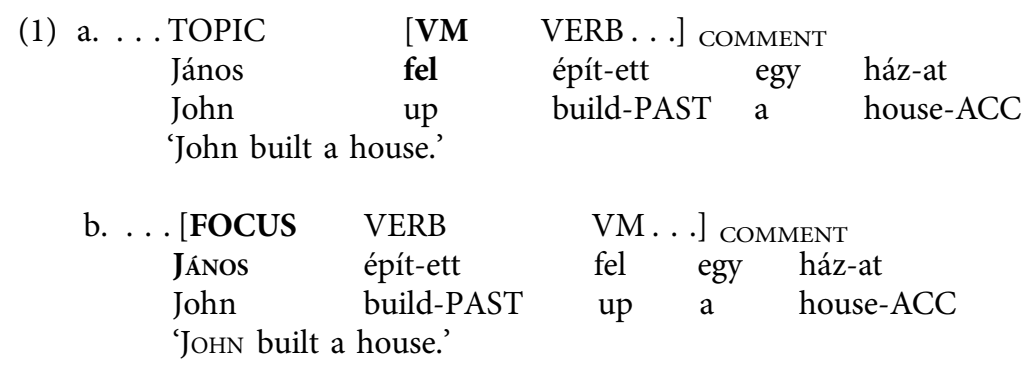

Hungarian is a stress-focus language, like Germanic and Romance. However, the position of the nuclear pitch accent (NPA) is less varied than in these latter languages. The NPA, marked by boldface in all our examples, falls by default on the leftmost element of the comment (É. Kiss, 2002; Kenesei \& Vogel, 1989). This typically coincides with the immediately pre-verbal constituent: in (1a) this is the VM, while in (1b) it is the narrow focus.

Due to mandatory syntactic focusing, cases of merely prosodically marked focus in which speakers need to rely exclusively on prosodic cues for focus identification are relatively scarce. This renders the functional load of prosody in the overall system of focus marking low compared to languages in which SFM is at best an option, as is generally the case in Germanic and Romance. We hypothesized that the systematic surface syntactic marking of focus diminishes the disambiguating role of prosodic marking also for the child acquiring PFM. Therefore we predicted the development of adult-like comprehension of PFM to be relatively late, in particular, to be delayed in comparison to Germanic and Romance languages, which the majority of prior work has concentrated on. ${ }^{2}$

\footnotetext{
${ }^{1}$ The default topic interpretation specifically of pre-verbal subjects is a robust effect in neutral Hungarian sentences (É. Kiss, 2002), but the default alignment of the subject grammatical function with the topic information structural role is a more general cross-linguistic tendency (Gundel, 1988).

${ }^{2}$ One aspect of Szendröi et al.'s (2018) study is related to this prediction. Unlike in languages like English, subject-focus in French is known to be preferably marked by a cleft construction rather than by mere stress-shift (Lambrecht, 1994). It may be expected along the lines of the main text reasoning that as a result, French children acquire adult-like PFM in the case of subject-focus later than in English. In their cross-linguistic study, Szendröi et al. failed to find such an effect.
} 
This prediction can only be tested in cases in which the focus happens not to be syntactically disambiguated. This is possible if the sentence happens to contain a verb lacking a VM. Ambiguity arises if such a verb is preceded by a phrase that may or may not function as the focus. For instance, in the absence of a VM, a sentence with SVX word order is potentially ambiguous between several information structural interpretations. It may be a 'neutral', broad focus sentence; this is the default information structure. As noted above, by default, the pre-verbal (definite, external argument) subject is interpreted as an aboutness topic, while the rest of the sentence is the comment (2a). Accordingly, in neutral SVX sentences the default NPA falls on the verb (the verb being the leftmost element of the comment). Alternatively, the sentence may have narrow focus on the verb (2b). In this case too the NPA is associated with the verb, this time qua narrow focus. Finally, the sentence may have narrow focus on the subject, in which case the NPA falls on the subject phrase (2c).

\begin{tabular}{lll} 
(2) a. SOPIC $\left[\begin{array}{lll}\mathbf{V} & \mathrm{X}\end{array}\right]$ COMMENT & \multicolumn{1}{c}{ (broad focus) } \\
János épít-ett egy & ház-at & (nem lustálkodott). \\
John build-PAST a & house-ACC & (not lazy.was) \\
'John built a house, he wasn't being lazy.' &
\end{tabular}
b. $S_{\text {TOPIC }}\left[\begin{array}{ll}\mathbf{V}_{\text {FOCUS }} & \mathrm{X}\end{array}\right]$ COMment $\quad$ (verb focus) János ÉPíT-ETT egy ház-at (nem BÉREL-T). John build-PAST a house-ACC (not rent-PAST) 'John BulLt a house, he didn't RENT one.'
c. $\left[\begin{array}{lll}\mathbf{S}_{\text {Focus }} & \mathrm{V} & \mathrm{X}\end{array}\right]$ COMment János épít-ett egy ház-at (nem MARI). John build-PAST a house-ACC (not Mary) 'JoHn built a house, not MARY.'
(subject focus)

In our comprehension experiment, to which we turn next, we made use of sentences falling into this general type of focus-ambiguous syntactic pattern.

\section{Method \\ Material and procedure}

To preclude the need on the participants' part for any extra semantic operation beyond identifying the focus (and thereby its relevant alternatives), and in order to make a cross-linguistic comparison feasible, we used the same task as the one in Szendröi et al. (2018), with some adjustments. In this sentence-picture verification task participants were required to accept any true assertions and to correct any false assertions made by a puppet about a display. Critical sentences (containing a focused constituent which is so marked only by prosody) were invariably false of the presented image. A correction was congruent with the focus of a test sentence if it corrected the focus-marked constituent of that sentence. ${ }^{3}$

\footnotetext{
${ }^{3}$ This notion corresponds to the concept of focus-congruence in the alternative semantics approach to focus meaning, as developed by Rooth (1992) (see also Krifka, 2008).
} 
Szendröi et al. (2018) used SVO sentences with either the subject or the object marked as the prosodic focus. Due to the mandatory fronting of the focused phrase to an immediately pre-verbal position, subject-focus and object-focus sentences have distinct word orders in Hungarian: in subject-focus sentences it is the subject, whereas in object-focus sentences it is the object that sits to the immediate left of the verb. For this reason, instead of using transitive verbs with a subject and an object placed in a subject-focus and an object-focus condition, we employed simple SV sentences (lacking a VM element or any post-verbal constituent), with prosodic focus either on the subject (S) or on the verb (V). Prosodic focus on $S$ involves non-default placement of the NPA (i.e., stress shift), and incurs a narrow subject focus interpretation (this information structure is represented in (2c) above). Prosodic focus on $\mathrm{V}$ licenses either a narrow verb focus reading (2b), or (since the comment of an SV sentence contains no material beyond the verb) a broad (VP) focus reading $(2 \mathrm{a})$ - these two are in principle indistinguishable from each other in the case of SV sentences. ${ }^{4}$ Thus, we created sentences with an invariable SV word order, which were disambiguated for their focus (S-focus vs. V-focus) only by prosodic prominence relations. S-focus and V-focus stimuli are exemplified in (3a) and $(3 \mathrm{~b})$, respectively.
(3) a. A MAJMOCSKA the monkey
trombitál.
plays.on.a.trumpet
'THE MONKEY is playing on a trumpet.'
S-focus condition
b. A majmocska the monkey
TROMBITÁL.
plays.on.a.trumpet
'The monkey IS PLAYING ON A TRUMPET.'

\author{
V-focus condition
}

Simultaneously with stimulus sentences, the participant was presented with a picture depicting three images side by side. In order to make our visual stimuli as similar as possible to Szendröi et al.'s (2018), which consisted of three pairs of an animal and an object, we created pictures that had the same overall structure: each of the three images contained an animal and an object such that the animal was engaged in some activity involving that object (see Figure 1). A noun corresponding to this object appeared as an incorporated nominal in a denominal verb in all our critical and control items (e.g., the verb trombitál 'play the trumpet' in (3a,b) is derived from the noun trombita 'trumpet' by adding a verbalizing suffix). The subject nouns and the verbs included in the experimental items are all commonly used words in a kindergarten environment.

Depending on whether the subject or the verb was interpreted as the focus of the sentence, participants were expected to correct the stimulus assertion in two different ways: either by correcting the subject or by correcting the verb. That is, in the case of example (3) and Figure 1, they were supposed to respond as "No, because THE TURTLE is playing on the trumpet" (subject correction) or as "No, because the monkey IS PLAYING ON THE DRUMS" (verb correction). The type of focus (S-focus vs. $\mathrm{V}$-focus) was a between-subject factor: half of the participants in each age group

\footnotetext{
${ }^{4}$ Similarly, prosodic focus on the object in Szendröi et al.'s (2018) SVO stimulus sentences also license a broad (VP) focus reading, via focus projection (Selkirk, 1984). This is because in the languages they examined the object bears the NPA as a default.
} 


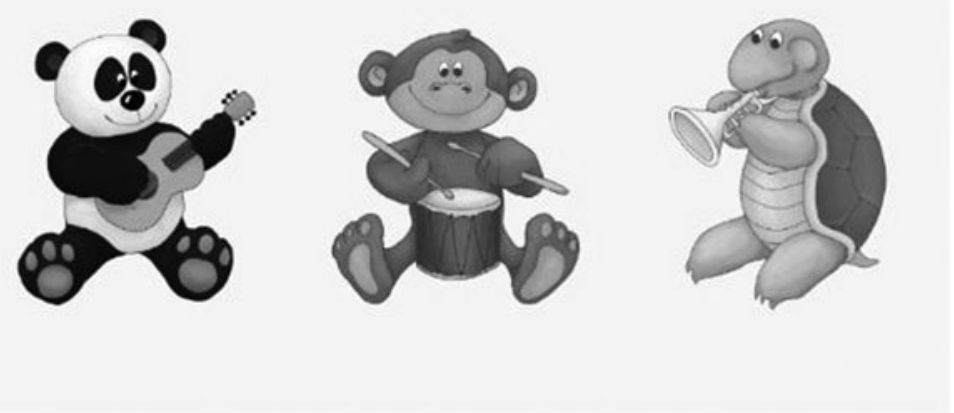

Figure 1. Picture presented with critical sentence $(3 a) /(3 b)$

received only S-focus sentences, and the other half received only $\mathrm{V}$-focus sentences as critical items.

Control items involved the same type of sentences as the critical items (either with subject focus or with verb focus), except that control sentences were true in view of the accompanying picture, and were expected to elicit acceptance rather than correction by the participant. In addition to critical and control items, the experiment also contained fillers, half of which involved a true sentence and the other half involved a false sentence. Filler sentences followed the scheme 'Every animal Vs', where V is a verb of the same type as those in the critical and control conditions.

Each experimental session consisted of 12 trials: after a short warm-up phase, participants judged 4 critical, 4 control and 4 filler sentence-picture pairs presented in two counterbalanced pseudo-randomized orders. In order to keep the audio stimuli constant, they were pre-recorded, and during the experiment they were played from a speaker placed inside a hedgehog puppet.

\section{Participants}

Monolingual Hungarian-speaking children in four different age groups were randomly selected as participants from public kindergartens and primary schools $(\mathrm{N}=84)$. Children who gave an erroneous response to two or more of the filler trials were excluded $(\mathrm{N}=4)$. Statistical analyses were based on data collected from 80 children: 14 four-year-olds (mean age: 4;5, SD =4.02), 22 five-year-olds (mean age: 5;5, $\mathrm{SD}=3.11$ ), 22 six-year-olds (mean age: $6 ; 4, \mathrm{SD}=3.43$ ), and 22 seven-year-olds (mean age: $7 ; 7, \mathrm{SD}=4.20)$. We also tested 20 adult native speakers as controls.

\section{Predictions}

We anticipated that in Hungarian the comprehension of mere prosodic focus marking would be delayed in comparison to the languages investigated by Szendröi et al. (2018), in which syntactic focus-marking is only an option. We expected this relative delay in acquisition to be revealed in two ways. Firstly, we predicted an age effect: namely, that the rate of Hungarian children's focus-congruent responses would increase with age before reaching adult-like levels, unlike in Szendröi et al. (2018), where no child age 
group differed from adults. Secondly, we predicted a language effect: the proportion of congruent responses to non-default narrow focus sentences (i.e., S-focus sentences) were expected to be lower in the case of Hungarian children than in the case of English, French and German children, at least in the youngest age group we investigated (i.e., four-year-olds). We anticipated a marked difference to emerge specifically in the subject-focus group, because in the other group (i.e., in verb-focus condition in Hungarian, and in the object-focus condition in English, French and German) the focused element functions in the respective languages as the prosodic focus BY DEFAult (see the discussion of (2a), and Footnote 2). As we did not make any assumptions regarding a potential cross-linguistic difference in the appeal of falling back on this default, no predictions were made with respect to cross-linguistic differences in the outcomes of the verb-focus condition and the object-focus condition, respectively.

\section{Results}

Figure 2 displays the distribution of correction types across age groups.

As our predictions concerned the rates of focus-congruent corrections of false stimulus sentences, our primary statistical analysis was based on the distribution of those responses that corrected the particular constituent in the incorrect statement that was prosodically marked as the focus (the same choice is made by Chen et al., 2019, who employed the same experimental task). Accordingly, responses were encoded as binary data based on whether they were congruent or non-congruent (the latter including incongruent corrections, as well as non-corrective responses). Binomial generalized mixed-effect models were run in $\mathrm{R}$ ( $\mathrm{R}$ Core Team, 2019) using the package lme4 (Bates, Maechler, Bolker \& Walker, 2015), including maximal converging random effects structure (Barr, Levy, Scheepers \& Tily, 2013), with the (non-)congruence of the response as the dependent variable, Focus TypE (subject-focus versus verb-focus) and AGE Group (four-, five-, six-, and seven-year-olds, and adults) as fixed effects, and PARTicipant (intercept) and ITEM (slope) as random effects.

The analysis showed that both Focus Type and Age Group affected the ratio of congruent responses significantly, and without a significant interaction. As far as Focus Type is concerned, we found that $\mathrm{V}$-focus sentences elicited more congruent corrections than S-focus sentences $\left(\chi^{2}(1)=20.78, p<0.001\right)$, without an interaction with age. The significant effect of AGE Group manifested itself in that the number of focus-congruent responses increased with age in both Focus TyPE conditions $\left(\chi^{2}(4)=14.17, p<0.001\right)$. Post hoc tests performed using the Anova () function (from the car package by Fox \& Weisberg, 2019) revealed that the fourand five-year-old groups did not differ from each other $(Z=0.35, p=0.73)$, and neither did seven-year-olds and adults $(Z=0.94, p=0.348)$. On the other hand, the response pattern of both four- and five-year-olds showed a significant difference from that of both seven-year-olds and adults (all four $Z>2.38, p<$ 0.016). The performance of six-year-olds differed neither from that of the younger groups (both $Z<1.78, p>0.075$ ) nor from that of the older groups (both $Z<1.71$, $p>0.087)$.

Because Szendröi et al. (2018) took the rate of subject-corrections as the dependent variable for their statistical analysis, in order to make a comparison with their findings more informative, we performed a second analysis of our data with their dependent 


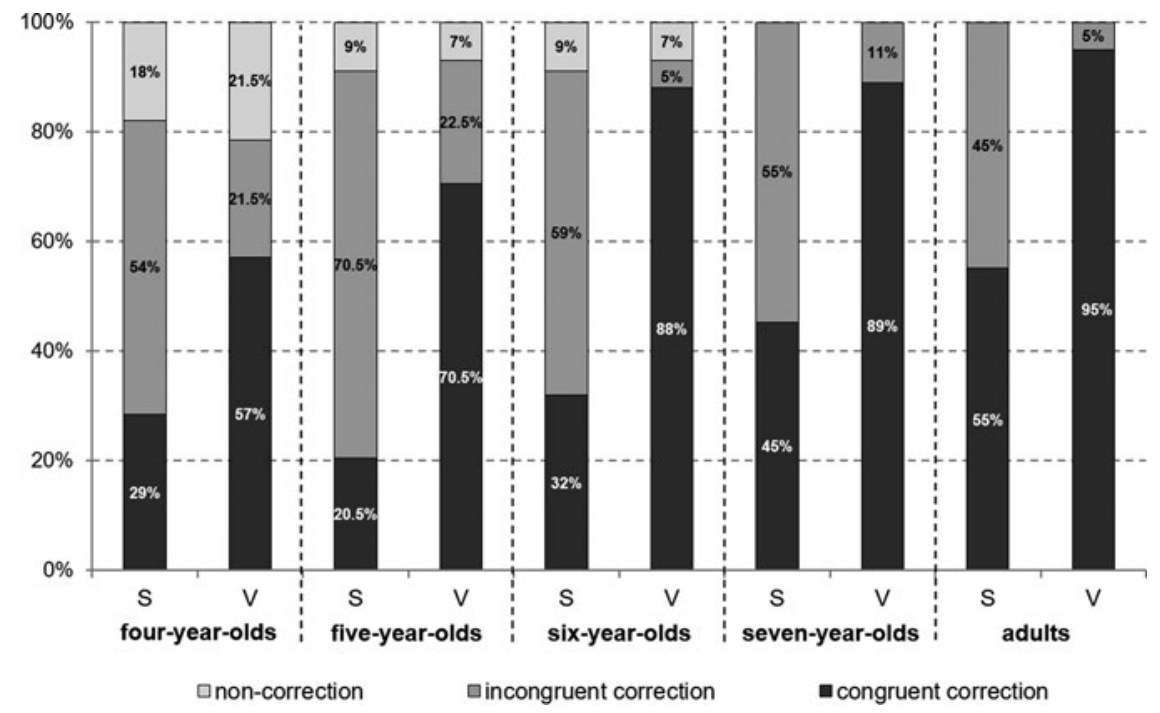

Figure 2. Proportion of correction types in the five age groups

measure. ${ }^{5}$ The binomial generalized mixed-effect model specified above yielded the following results. Focus TyPE had a significant main effect $\left(\chi^{2}(1)=7.13, p=0.008\right)$ and showed a significant interaction with AgE Group $\left(\chi^{2}(4)=10.84, \mathrm{p}=0.028\right)$.

This interaction was explored using the Anova() function, which revealed that Focus TyPE differently affected the response patterns of four- and five-year-olds on the one hand, and those of seven-year-olds and adults on the other (four-year-olds and seven-year-olds: $Z=1.65, p<0.05$; five-year-olds and seven-year-olds: $Z=2.08$, $p<0.05$; four-year-olds and adults: $Z=2.37, p<0.05$; five-year-olds and adults: $Z=2.84, p<0.01)$. This was confirmed by a series of Fisher's exact tests that investigated the effect of Focus TyPE within each age group. It was found that while Focus Type did not affect the ratio of subject-corrections in the groups of fourand five-year-olds (four-year-olds: $\chi^{2}(1)=0.38, p=0.54$; five-year-olds: $\chi^{2}(1)=0.07$, $p=0.8$ ), it did so in all older groups (six-year-olds: $\chi^{2}(1)=11, \quad p<0.001$; seven-year-olds: $\chi^{2}(1)=12.57, p<0.001$; adults: $\chi^{2}(1)=23.81, p<0.001$ ).

To further examine the interaction found, we tested the effect of AGE GROUP on subject-corrections within each of the two focus conditions, using binomial generalized mixed-effect models with the same random effect structure as above. To compensate for the low number of participants per age group within one focus condition, we grouped participants into three AGE RANGES following the overall pattern of age-dependent differences in congruent responses that emerged from the analysis above: (i) four-to-five-year-olds, (ii) six-year-olds, and (iii) a group including seven-year-olds and adults.

While in the case of participants assigned to the $\mathrm{V}$-focus condition $(\mathrm{N}=50)$, AGE RANGE gave rise to no significant differences $\left(\chi^{2}(2)=5.64, p=0.059\right)$, in the case of participants of the $\mathrm{S}$-focus condition $(\mathrm{N}=50)$ a significant effect of AGE RANGE was

\footnotetext{
${ }^{5}$ The rates of subject-corrections in the $\mathrm{V}$-focus condition are represented in Fig. 2 above as incongruent correction'.
} 
detected $\left(\chi^{2}(2)=6.03, \mathrm{p}<0.05\right)$. Pair-wise comparisons revealed a pattern not unlike the one found in the analysis of congruent responses above: four-to-five-year-olds significantly differed from the group comprised of seven-year-olds and adults $(Z=$ 2.4, $p<0.05$ ), while six-year-olds differed from neither the younger nor the older group (both $Z<1.48, \mathrm{p}>0.14$ ).

\section{Discussion}

Based on the hypothesis that the systematic syntactic marking of focus in Hungarian curbs the disambiguating role of prosodic marking for the child, we expected that in sentences in which focus is only disambiguated by prosody, adult-like comprehension of PFM will be attained relatively late, with a delay in comparison to the languages investigated in Szendröi et al. (2018).

One way in which we expected this delay to reveal itself is through the effect of age. We found that age had a significant effect on the rate of congruent responses, with the turning point being around the age of six. The response pattern of four- and five-year-olds was not adult-like, and in fact it also differed from that of seven-year-old children. The performance of six-year-olds was intermediate in that they did not differ from either the younger or the older age groups.

Concentrating on the S-focus condition, the analysis of the rate of congruent subject-corrections showed a similar overall pattern in that four-to-five-year-olds differed from the group of seven-year-olds and adults, while six-year-olds differed from neither of these two. That the age of six represents a turning point in developmental trajectory is also confirmed by the finding that it is only from this age onward that children's rate of subject-corrections reflects a sensitivity to focus type.

The fact that the Hungarian children in our experiment only reached adult-like levels by the age of six strikingly confirms our prediction of an age effect in this language. Recall that, by contrast to our findings, in Szendröi et al. (2018) age had no effect either as a main factor or in interaction with focus type. Although when using the same dependent variable (the rate of subject-corrections) as in that study, age displayed no main effect in our data either, it exhibited a significant interaction with focus type. This interaction is due to the fact that, overall, in the $\mathrm{V}$-focus condition the ratio of subject-corrections moderately decreases, while in the S-focus condition it considerably increases with age (yielding a significant AgE RANGE effect). This kind of interaction is precisely what is predicted if the proportion of congruent corrections increases with age in both focus types: the pattern we indeed detected in Hungarian in the form of a main effect of age on congruent responses without interaction with focus type. In fact, given this increase in congruent reactions in both focus types in Hungarian, no main age effect is expected in this language when analyzing the rate of subject-corrections as the dependent measure in the complete model. What renders the pattern of subject-corrections in Hungarian different from that in the languages analyzed by Szendröi et al. (2018) is that, in the latter, age was not only found to lack a main effect, but, crucially, it also showed no interaction with focus type. Taken together, the contrast between our findings and those of Szendröi et al. indirectly reinforces the latter authors' conclusion that in their languages overall performance does not significantly change with age, and children's behavior in the task is adult-like already at the earliest age they examined. Another way in which a relative delay was expected to be discovered was a difference between the actual rate of congruent responses in the subject-focus condition in Hungarian 
and the rate of congruent responses in the same condition in English, French and German - at least in the youngest age group we investigated (i.e., four-year-olds). This prediction too is borne out by the data. In fact, the rate of congruent subject-corrections in Hungarian (29\%) is about half of the corresponding rates in English (62\%), French (58\%), and German (65\%) not only at age four, but also at ages five $(21 \%$ vs. $64 \%, 45 \%, 56 \%)$ and six $(32 \%$ vs. $72 \%, 50 \%, 50 \%)$. To compensate for the small number of participants comprising these age groups within the individual focus conditions of each tested language, and because these particular age groups showed no significant difference in the subject-focus condition in any of these languages, below we present a comparison of the ratios based on aggregated results of four-to-six-year-olds (Figure 3). Even though this comparison is based on a crude contrast between means, due to the size of the difference found, it is nevertheless strongly suggestive.

The fact that Hungarian four-to-five-year-old children do not exhibit an adult-like pattern of comprehension of PFM, while their English, French and German peers do, taken together with the fact that in Hungarian the rate of congruent subject-corrections at ages four to six is about half of the corresponding rates in English, French and German, reveals that, as predicted, the acquisition of the comprehension of PFM is delayed in Hungarian as compared to the other three languages.

Since the task in Szendröi et al.'s (2018) experiment and ours was the same, the uncovered differences cannot be easily ascribed to task effects; the tasks employed in the two experiments are unlikely to have placed different constraints on the manifestation of identical underlying knowledge. Instead, the relative delay in the comprehension of PFM we have found in Hungarian can be readily explained as an indirect effect of the prevalence of SFM and the concomitant low functional load of PFM in this language.

It is potentially illuminating to compare our results with Chen et al.'s (2019), who, using the same task as Szendröi et al. (2018), found even lower rates of congruent corrections by Mandarin children in the subject-focus condition (cca. 15\%) than we did. Adopting the assumption that Mandarin has a default sentence-final focus position (L. Xu, 2004; but see Li, 2009, for an opposing view), Chen et al. speculate that this low performance may be due to Mandarin's relying on word order more than on prosody in marking focus. We believe that even if SFM is a factor in Mandarin-speaking children's response patterns, it can only play a lesser role.

First, children's congruent response rate in the subject-focus condition in Mandarin is remarkably lower than the corresponding rate Szendröi et al. found in German (where it is above $40 \%$ even in three-year-olds), despite the fact that German is not qualitatively different from Mandarin in that both languages can, and in some cases prefer to, mark focus by word order. Second, unlike in Mandarin, SFM is not merely a possible or preferential option in Hungarian, but it is mandatory. In spite of this, rather than performing more poorly on the subject-focus condition, Hungarian four-year-olds gave more congruent responses (29\%) than their Mandarin peers.

Instead, a factor that may have weighed more in Mandarin children's extreme poor performance is the non-uniformity in the system of PFM in the language. Unlike in Germanic and Romance, marking by prominence is not mandatory in Mandarin when a sentence has broad focus ( $\mathrm{Li}, 2009$; $\mathrm{Y}$. Xu, 1999) or when narrow focus is marked syntactically ( $\mathrm{Li}, 2009$; L. Xu, 2004; in some cases the syntactically marked focus can even be prosodically non-prominent). Indeed, while in Germanic, 


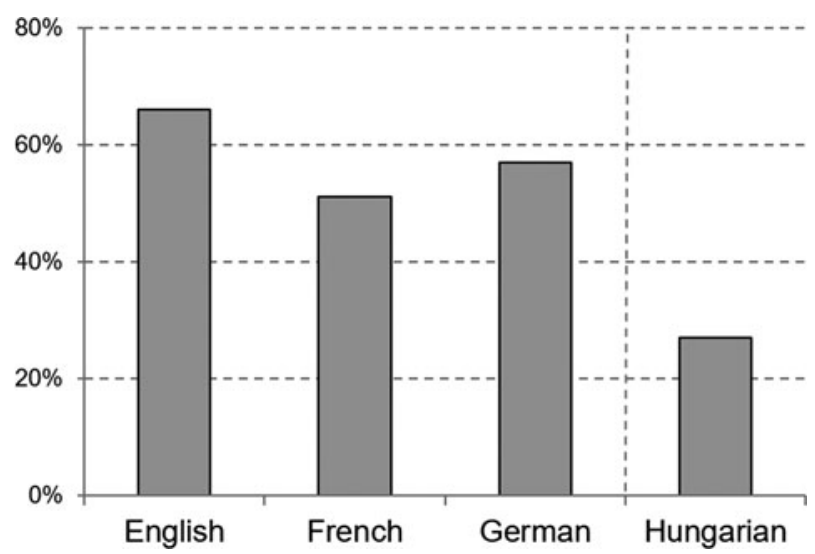

Figure 3. Average ratios of congruent S-focus corrections by four-to-six-year-olds in the present study and in Szendrői et al. $(2018)^{6}$

Romance and Hungarian PFM is phonological, in Mandarin it has been argued to be merely phonetic in nature (Wang, Xu \& Ding, 2017; Yang \& Chen, 2018). Arguably, this lack of uniformity in PFM makes prosodic prominence-marking a highly unreliable cue of focus in the acquisition process. ${ }^{7}$

A final result to be discussed here is the effect of Focus Type we have found: the proportion of congruent responses in the $\mathrm{V}$-focus condition was consistently higher across all age groups and across all items than in the S-focus condition. It is due to the relatively high rate of verb-corrections performed in the $\mathrm{V}$-focus condition from the earliest investigated age onward that AGE RANGE had no significant effect on the rate of subject-corrections in this focus condition, while it did so in the S-focus condition. These asymmetries between the two focus types may have a number of sources. First, the general information structural default is a broad focus interpretation, and, further, as noted in the Introduction, in Hungarian a pre-verbal definite subject is routinely assigned a topic interpretation. In other words, the default information structure of our SV target sentences is $\mathrm{S}=$ topic, $\mathrm{V}=$ focus (in this interpretation, the verb, comprising on its own the entire VP, functions as a broad focus). A preference for this default information structure may have contributed to a bias in favor of ' $\mathrm{V}=$ focus' responses in both focus conditions across all age groups, reflected as a bias against producing subject-corrections. This bias may have boosted the rate of congruent (verb-)corrections in the $\mathrm{V}$-focus condition, while it militated against congruent (subject-)corrections in the S-focus condition. Another potentially relevant additional factor, which may have indirectly given rise

\footnotetext{
${ }^{6}$ This figure was created based on Figure 2 of Szendröi et al. (2018, p. 234).

${ }^{7}$ Yet another relevant property of Mandarin that may have contributed to children's low performance is that it is a tone-language, in which pitch is used not only for intonational, but also for lexical functions (Chen et al., 2019). If this property indeed plays a role, then our findings from Hungarian can be viewed as the inverse of Chen et al.'s (2019). While in Mandarin, it would be the alternative, systematic non-intonational (lexical tonal) functions of the phonetic markers of focus that delay acquisition, in Hungarian it is the predominance of alternative, non-intonational (syntactic) means of focus-encoding that has the same procrastinating effect.
} 
to a similar effect, is the animacy of subjects: this may have biased participants in favor of using the subject in the responses as a topic. ${ }^{8}$

The influence of these biasing factors in the production of responses is not precluded by the correction task itself, which may be considered a limitation of our study. Indeed, they apparently also played a role in the adults' response patterns, causing their rate of subject-corrections to be far from ceiling in the S-focus condition. That this is a property of the task rather than a consequence of the reduced role of prosodic focus marking in the target grammar of Hungarian is supported by the fact that adults in the S-focus condition were not near ceiling levels in English, French and German either, despite the comparatively high functional load of prosodic cues in focus-marking in these latter languages.

Although the above-presented two different statistical models of the complete dataset converge on the key finding of the effect of age in Hungarian, another clear limitation is related to the relatively low number of participants that comprise each age group when analyzing the role of Focus Type by AgE Group and the role of AGE Group by Focus TYPE. This was partly compensated by regrouping the participants into three AgE RANGES specifically for the analysis of the responses within each of the two focus conditions.

\section{Conclusion}

This paper makes a strong case that, similarly to the acquisition of the production of prosodic focus-marking (Chen, 2018), the developmental trajectory of the comprehension of prosodic focus-marking is also significantly affected by the cross-linguistic variation found in the marking of focus. Specifically, our results show that one key determining factor is the prevalence of alternative (in Hungarian: syntactic) means of focus-encoding in a given language. We have argued that it is due to this grammatical property that Hungarian children identify a purely prosodically marked focus in an adult-like manner only from six years of age onward, while their English, French and German peers perform in an adult-like fashion already as early as age three. The conclusion that the presence of systematic syntactic focus-marking has a robust procrastinating effect on the development of the comprehension of prosodic focus-marking suggests that children may not universally have Full Competence in the comprehension of prosodic focus-marking at early pre-school ages.

Acknowledgements. The research reported here was funded by the Hungarian National Research and Innovation Fund (grant no. KH-130558), and it was also supported by the Thematic Excellence Program of the Hungarian Ministry for Innovation and Technology (project no. 2020-4.1.1-TKP2020, Theoretical and Experimental Linguistics). The authors thank the anonymous reviewers and the section editor for this paper, Ana Lucia Santos, for their insightful comments and helpful suggestions.

\footnotetext{
${ }^{8}$ Szendrői et al. (2018) identify essentially the same factors as potentially contributing to an analogous asymmetry in their results, namely, that the proportion of congruent responses was lower in the subject-focus condition than in the other condition in most age groups in all three languages. This suggests that the relatively low rate of subject-corrections (55\%) performed by Hungarian adults in the subject-focus condition is not due to the restricted functional load of PFM in Hungarian. For the potential role of default information structural interpretation in four-year-olds' non-adult-like pattern of association of nur 'only' with the focus of the sentence in German, see Höhle, Fritzsche and Müller (2016) and references therein.
} 


\section{References}

Barr, D. J., Levy, R., Scheepers, C., \& Tily, H. J. (2013). Random effects structure for confirmatory hypothesis testing: Keep it maximal. Journal of memory and language, 68(3), 255-78.

Bates, D., Maechler, M., Bolker, B., \& Walker, S. (2015). Fitting linear mixed-effects models using lme4. Journal of Statistical Software, 67(1), 1-48.

Berger, F., \& Höhle, B. (2012). Restrictions on addition: children's interpretation of the focus particles auch 'also' and nur 'only' in German. Journal of Child Language, 39(2), 383-410.

Bergsma, W. (2006). (Un)stressed ook in Dutch. In V. van Geenhoven (ed.), Semantics in acquisition (pp. 329-48). Dordrecht: Springer.

Bloom, L. (1970). Language Development: Form and Function in Emerging Grammars. Cambridge, MA: MIT Press.

Brown, R. (1973). A First Language. Cambridge, MA: Harvard University Press.

Chen, A. (2018). Get the focus right across languages: Acquisition of prosodic focus-marking in production. In P Prieto, \& N. Esteve-Gibert (eds.), Prosodic development in first language acquisition (pp. 295-314). Amsterdam: John Benjamins.

Chen, H-C., Szendröi, K., Crain, S., \& Höhle, B. (2019). Understanding prosodic focus marking in Mandarin Chinese: data from children and adults. Journal of Psycholinguistic Research, 48(1), 19-32.

Chen, S-H. E. (1998). Surface cues and the development of given/new interpretation. Applied Psycholinguistics, 19(4), 5535-82.

Costa, J., \& Szendrői, K. (2006). Acquisition of focus marking in European Portuguese - Evidence for a unified approach to focus. In V. Torrens, \& L. Escobar (eds.), The acquisition of syntax in Romance languages (pp. 319-30). Amsterdam: John Benjamins.

Cruttenden, A. (1985). Intonation comprehension in ten-year-olds. Journal of Child Language, 12(3), 643-61.

Cutler, A., \& Swinney, D. A. (1987). Prosody and the development of comprehension. Journal of Child Language, 14(1), 145-67.

Fox, J., \& Weisberg, S. (2019). An R Companion to Applied Regression, Third edition. Thousand Oaks CA: Sage. https://socialsciences.mcmaster.ca/jfox/Books/Companion/

Gervain, J., \& Werker, J. F. (2013). Prosody cues word order in 7-month-old bilingual infants. Nature Communications, 4, 1490.

Gualmini, A., Crain, S., Meroni, L., Chierchia, G., \& Guasti, M. T. (2001). At the semantics/pragmatics interface in child language. In R. Hastings, B. Jackson, \& Zs. Zvolenszky (eds.), Semantics and Linguistic Theory 11. (pp. 231-47). Ithaca, NY: Cornell University.

Gualmini, A., Maciukaite, S., \& Crain, S. (2003). Children's insensitivity to contrastive stress in sentences with 'only'. University of Pennsylvania Working Papers in Linguistics, 8(1), 87-100.

Gundel, J. K. (1988). Universals of topic-comment structure. In M. Hammond, E. A. Moravcsik, \& J. Wirth (eds.), Studies in Syntactic Typology (pp. 209-232). Amsterdam: John Benjamins.

Hornby, P. A. (1971). Surface structure and the topic-comment distinction: a developmental study. Child Development, 42(6), 1975-88.

Höhle, B., Berger, F., Müller, A., Schmitz, M., \& Weissenborn, J. (2009). Focus particles in children's language: production and comprehension of auch 'also' in German learners from 1 year to 4 years of age. Language Acquisition, 16(1), 36-66.

Höhle, B., Bijeljac-Babic, R., Herold, B., Weissenborn, J., \& Nazzi, T. (2009). Language specific prosodic preferences during the first half year of life: evidence from German and French infants. Infant Behavior \& Development, 32(3), 262-74.

Höhle, B., Fritzsche, T., \& Müller, A. (2016). Children's comprehension of sentences with focus particles and the role of cognitive control: An eye tracking study with German-learning 4-year-olds. PLOS ONE, 11(3), e0149870.

Kenesei, I., \& Vogel, I. (1989). Prosodic Phonology in Hungarian. Acta Linguistica Hungarica, 39, 149-93.

Kiss, K. É. (2002). The Syntax of Hungarian. Cambridge: Cambridge University Press.

Krifka, M. (2008). Basic notions of information structure. Acta Linguistica Hungarica, 55(3-4), 243-76.

Lambrecht, K. (1994). Information structure and sentence form: Topic, focus, and the mental representation of discourse referents. Cambridge, MA: Cambridge University Press. 
Li, K. (2009). The information structure of Mandarin Chinese: syntax and prosody. PhD dissertation, University of Washington.

Lieberman, P. (1967). Intonation, perception, and language. Cambridge, MA: MIT Press.

Menyuk, P. (1969). Sentences children use. Cambridge, MA: MIT Press.

Papafragou, A., \& Musolino, J. (2003). Scalar implicatures: Experiments at the semantics-pragmatics interface. Cognition, 86(3), 253-82.

R Core Team. (2019). R: A language and environment for statistical computing. $R$ Foundation for Statistical Computing. Vienna, Austria. https://www.R-project.org/

Rooth, M. (1992). A theory of focus interpretation. Natural Language Semantics, 1, 75-116.

Sauermann, A., Höhle, B., Chen, A., \& Järvikivi, J. (2011). Intonational marking of focus in different word orders in German children. In M. B. Washburn et al. (eds.), Proceedings of the 28th West Coast Conference on Formal Linguistics (pp. 313-22). Somerville, MA: Cascadilla Project.

Schmitz, M., Höhle, B., Müller, A., \& Weissenborn, J. (2006). The recognition of the prosodic focus position in German-learning infants from 4 to 14 months. In S. Ishihara, M. Schmitz, \& A. Schwarz (eds.), Interdisciplinary studies on information structure 5 - Working papers of the SFB632 (pp. 187208). Potsdam: Universitätsverlag Potsdam.

Sekerina, I. A., \& Trueswell, J. C. (2012). Interactive processing of contrastive expressions by Russian children. First Language, 32(1-2), 63-87.

Selkirk, E. (1984). Phonology and syntax: The relation between sound and structure. Cambridge, MA: MIT Press.

Szendröi, K., Bernard, C., Berger, F., Gervain, J., \& Höhle, B. (2018). Acquisition of prosodic focus marking by English, French, and German three-, four-, five- and six-year-olds. Journal of Child Language, 45(1), 219-41.

Wang, B., Xu, Y., \& Ding, Q. (2017). Interactive prosodic marking of focus, boundary and newness in Mandarin. Phonetica 75, 24-56.

Wellmann, C., Holzgrefe, J., Truckenbrodt, H., Wartenburger, I., \& Höhle, B. (2012). How each prosodic boundary cue matters: Evidence from German infants. Frontiers in Psychology, 3, 580.

Wells, B., Peppé, S., \& Goulandris, N. (2004). Intonation development from five to thirteen. Journal of Child Language, 31(4), 749-78.

Wieman, L. (1976). Stress patterns in early child language. Journal of Child Language, 3, 283-6.

Xu, L. (2004). Manifestation of informational focus. Lingua, 114 (3). 277-99.

Xu, Y. (1999). Effects of tone and focus on the formation and alignment of f0 contours. Journal of Phonetics, 27, 55-105.

Yang, A., \& Chen, A. (2018). The developmental path to adult-like prosodic focus-marking in Mandarin Chinese-speaking children. First Language, 38(1), 26-46.

Cite this article: Surányi B, Pintér L (2022). Children's comprehension of prosodically marked focus in Hungarian: How mandatory syntactic focus-marking affects the trajectory of acquisition. Journal of Child Language 49, 824-838. https://doi.org/10.1017/S0305000921000313 